REVIEW ARTICLE

\title{
Inflammation and infection in plasma cell disorders: how pathogens shape the fate of patients
}

\author{
Jessica Caro ${ }^{1}$, Marc Braunstein ${ }^{1}$, Louis Williams ${ }^{1}$, Benedetto Bruno ${ }^{1}$, David Kaminetzky ${ }^{1}$, Ariel Siegel ${ }^{1}$, Beatrice Razzo ${ }^{1}$, Serge Alfandari ${ }^{2}$, \\ Gareth J. Morgan (iD) ${ }^{1}$, Faith E. Davies ${ }^{1}$ and Eileen M. Boyle (iD ${ }^{1 凶}$
}

(c) The Author(s), under exclusive licence to Springer Nature Limited 2022

The role of infection and chronic inflammation in plasma cell disorders (PCD) has been well-described. Despite not being a diagnostic criterion, infection is a common complication of most PCD and represents a significant cause of morbidity and mortality in this population. As immune-based therapeutic agents are being increasingly used in multiple myeloma, it is important to recognize their impact on the epidemiology of infections and to identify preventive measures to improve outcomes. This review outlines the multiple factors attributed to the high infectious risk in PCD (e.g. the underlying disease status, patient age and comorbidities, and myeloma-directed treatment), with the aim of highlighting future prophylactic and preventive strategies that could be implemented in the clinic. Beyond this, infection and pathogens as an entity are believed to also influence disease biology from initiation to response to treatment and progression through a complex interplay involving pathogen exposure, chronic inflammation, and immune response. This review will outline both the direct and indirect role played by oncogenic pathogens in PCD, highlight the requirement for large-scale studies to decipher the precise implication of the microbiome and direct pathogens in the natural history of myeloma and its precursor disease states, and understand how, in turn, pathogens shape plasma cell biology.

Leukemia (2022) 36:613-624; https://doi.org/10.1038/s41375-021-01506-9

\section{INTRODUCTION}

Multiple myeloma (MM) is a cancer of plasma cells that leads to dysregulation of the bone marrow microenvironment, resulting in cytopenias, bone resorption, and monoclonal antibody production. Plasma cells are terminally differentiated B-cells that, without further antigenic stimulation, continuously secrete antibodies. In healthy patients, the adaptive immune response is protective against many pathogens and forms the backbone of memory responses to preventative measures such as vaccination.

Infection is an ill-defined symptom in plasma cell disorders (PCD), such as MM and its precursor phases. Although it burdens every stage of disease, significantly affecting morbidity and mortality, infection is not part of the diagnostic criteria for symptomatic disease requiring treatment. The role of infection in disease initiation and progression remains debated. Although some argue that oncogenic viruses and chronic inflammation are key in the pathogenesis of PCD, the evidence supporting this hypothesis remains scarce. Recently, renewed interest in oncogenic pathogens from microbiome studies has highlighted the interaction between disease progression and homeostasis related to various pathogenic signatures.

Here we review the evidence underlying how pathogens shape PCD and how, in turn, PCD impact immune response against infections throughout disease stages.

\section{ROLE OF INFECTION, INFLAMMATION, AND PATHOGENS IN} THE PATHOGENESIS OF PCD

Infection is estimated to cause one in five cancer cases worldwide. [1] Infectious cancer agents can be divided into direct carcinogens, which express viral oncogenes that directly contribute to oncogenic transformation, and indirect carcinogens that cause cancer through chronic inflammation and acquisition of driver mutations. Although this simple dichotomization provides a helpful framework to understand the role of pathogens in PCD, it does not account for their role in immune modulation and cancer progression.

\section{Pathogens as direct carcinogens in PCD}

Viruses have repeatedly been considered as a possible cause for cancer, and PCD are no exception to this rule. Oncogenic viruses are believed to contribute to the development of immunosuppressionrelated cancers [2], with the prime example being Kaposi's sarcoma and HHV8. There is some evidence supporting an increased risk of PCD in immunocompromised patients. Prior to the development of highly active antiretroviral therapies (HAART), the incidence of monoclonal gammopathy of undetermined significance (MGUS) in HIV patients was believed to be significantly higher than in non-HIV patients, ranging from 4-26\% [3]. When considering $M M$, the standardized incidence ratios (SIRs) from 1980-1996 and 1996-2002 were 2.60 and 2.20 , respectively, suggesting the incidence decreased

${ }^{1}$ Myeloma Research Program, Perlmutter Cancer Center, NYU Langone Health, New York, NY, USA. ${ }^{2}$ Service de Réanimation et Maladies Infectieuses, CH Gustave Dron, Tourcoing,

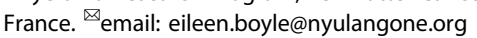


with effective HAART [2]. When considering transplant patients, several publications have suggested a higher risk of MM compared to the general population $[4,5]$. Of note, $39 \%$ of cases were EBVpositive, far higher than the rates in MM that develop in nonimmunosuppressed patients, suggesting they may be a separate disease entity that lie somewhere on the spectrum of post-transplant lymphoproliferative disorders. Although a role for EBV in MM has not yet been established, there are occasional case reports $[6,7]$ and in vitro evidence suggesting that aberrant EBV latent infection may contribute to the etiology of MM [8].

Loss of surveillance for specific viral cytotoxic T-cell epitopes without generalized immunosuppression, as might occur during aging, is also likely to promote cancers caused by viruses. [9] Although there is a clear association between PCD and aging [10], and there are age-specific genetic changes in MM [11], none of them have currently been linked directly to infection.

Overall, there is no definitive evidence supporting the role for pathogens as a direct cause of PCD, but recent work has highlighted a possible indirect role.

\section{Pathogens as indirect carcinogens in PCD}

For over 150 years, it has been suggested that chronic inflammation enhances cell proliferation. Chronic inflammation has been associated with MGUS and MM in specific subsets such as Gaucher's disease and even sporadic cases of MGUS, where long-term immune activation by lysolipids may underlie disease [12]. This is in part why obesity and poverty have been suggested to increase one's risk of PCD [13]. Infectious pathogens, including carcinogenic viruses (EBV, $\mathrm{HCV}$, and HPV) and bacteria (Helicobacter pylori), are the targets of approximatively $23 \%$ of purified monoclonal lgG from MGUS, smoldering $\mathrm{MM}(\mathrm{SMM})$, and $\mathrm{MM}$ patients, which is more that in normal sera [14]. This may also explain the association between MM and HCV in population-based studies [15]. The working hypothesis is that abnormal immune response, either to self-proteins or to infectious pathogens, increases the risk of genetic alteration and subsequent malignant transformation to overt MM. Long-term antigenic stimulation may also promote genomic instability in $\mathrm{MM}$ by engaging cytidine deaminases, which has been suggested to explain the progression from SMM to MM [16].

\section{Pathogens as modulators of immune-surveillance in PCD}

Besides pathogens' oncogenic role, there is a current body of evidence supporting their role in immunomodulation and disease progression.

The microbial environment has long been linked to mucosal inflammation, autoimmunity, and development of gastrointestinal malignancies. More recently, commensal bacteria in the gut are suspected to contribute to the development of extramucosal tumors, including MM [17]. Th17 cells are particularly critical in the gut microbiota interactions relevant in tumor growth. In addition to protecting against bacterial and fungal infections, Th17 cells secrete inflammatory cytokines, including IL-17, which promotes plasma cell growth through an IL-6-STAT3 signaling pathway and local activation of eosinophils. The accumulation of IL-17 producing cells in the BM has been shown to drive progression of $\mathrm{MM}$ and may even represent an early biomarker for high-risk SMM patients [18].

Increasing evidence suggests that the gut microbiota impact the response and toxicity of immune-based therapies $[19,20]$. This was first analyzed in the setting of allogeneic stem cell transplantation for hematologic malignancies, where patients are often treated with immunosuppressant agents and broadspectrum antibiotics that significantly alter the microbiota composition (called dysbiosis) and may affect the outcome of the engrafted stem cells. In these patients, lower diversity of gut microbiota is associated with lower OS, higher transplant-related mortality, and increased onset of graft-versus-host disease [21]. Intestinal microbiota composition was later shown to potentially affect treatment response in patients not undergoing stem cell transplantation. Patients who achieve minimal residual disease

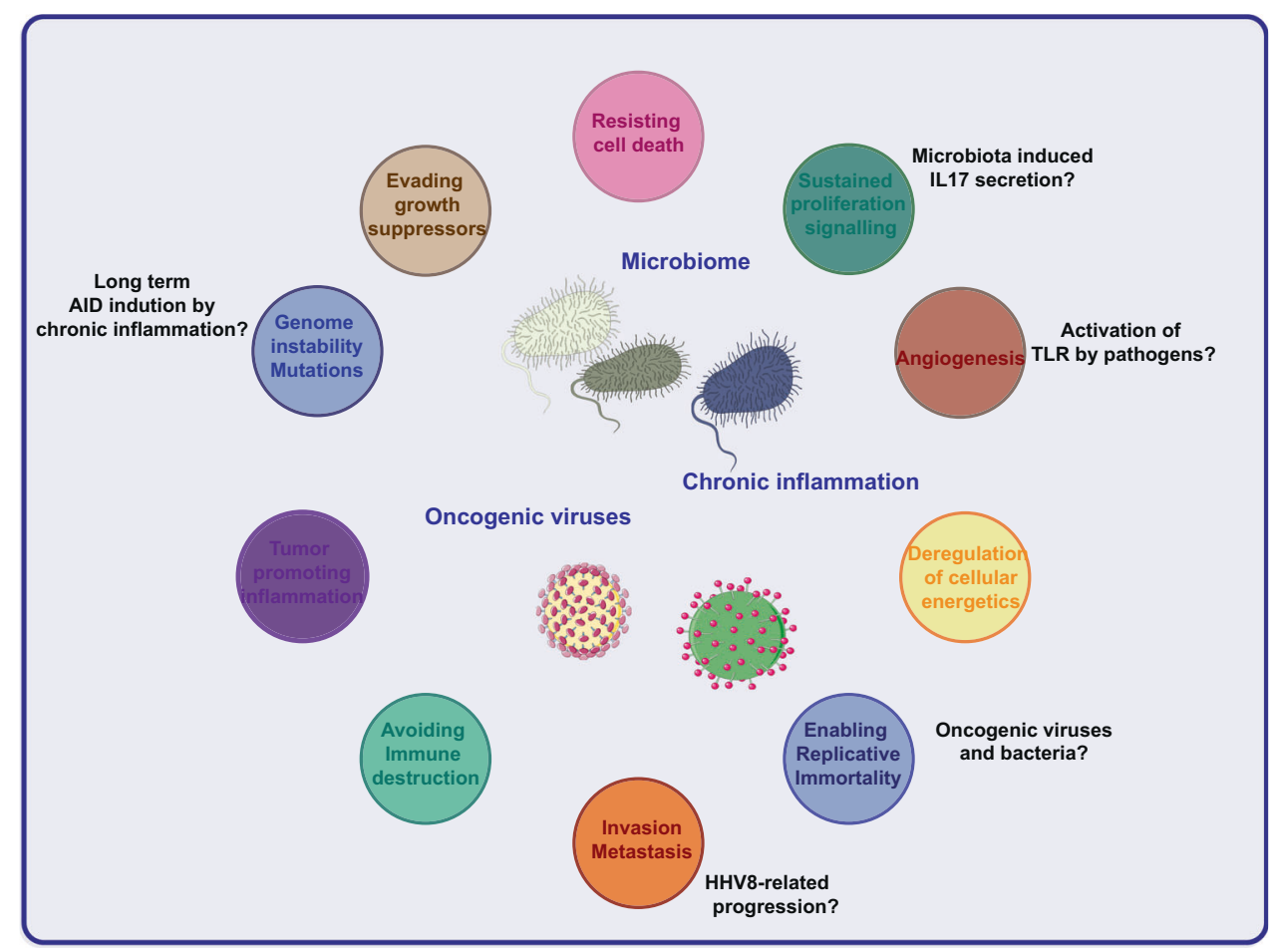

Fig. 1 Impact of pathogens on the hallmarks of plasma cell disorders. An increasing body of evidence supports an effect of the microbiota, chronic inflammation, and oncogenic virus on various cancer hallmarks, including genomic stability, angiogenesis disease progression, and replicative immortality. 
(MRD) negativity after upfront treatment for newly diagnosed MM (NDMM) were noted to have a higher relative abundance of Eubacterium hallii compared to patients with MRD positivity [22].

\section{Future research strategies in PCD}

As pathogens influence many hallmarks of cancer mainly through their influence on the microenvironment (Fig. 1), identification of infectious carcinogens on a large scale may open options for early prevention strategies or specific therapies, such as drugs targeting latent viruses or immunological therapies at early disease stages. Unfortunately, it does not guarantee a cure, as the reversibility of these early oncogenic processes has yet to be ascertained.

Anecdotal retrospective studies of the microbiome are available but insufficient to build interception strategies and suffer from many confounding factors that await confirmation. The PROMISE (NCT03689595) and SMRT studies should yield valuable information in the premalignant setting, but microbiome evaluations have yet to be included in large scale clinical trials at the myeloma stage.

\section{ROLE OF INFECTION IN OUTCOME OF MM}

Beyond their role in disease initiation and progression, infections shape outcomes in PCD, which are influenced by factors related to disease, patient, and PCD treatment.

\section{Epidemiology}

MGUS has a relatively high prevalence in the general population ( $3 \%$ over age 50 and $5 \%$ over age 70 ). Patients with MGUS have a two-fold higher risk of infection compared to the general population, with the highest risk noted at monoclonal protein concentrations $>2.5 \mathrm{~g} / \mathrm{dL}$ at diagnosis [23], Even though MGUS is often incidentally diagnosed and does not require any treatment, this susceptibility to infections is increasingly relevant as the population continues to age and there are more MGUS cases.

MM patients have a seven-fold higher risk of infection compared to the general population [24]. This risk of infection fluctuates over time, noted to be highest in the first few months of diagnosis and decreases with response to treatment. In the United-Kingdom MRC Trial, $10 \%$ of patients died within 60 days of diagnosis, with $45 \%$ of deaths due to infection, many in elderly patients [25]. Infection is the leading cause of early mortality in elderly MM patients, who have age-related immune dysfunction and comorbidities [26].

Infection is attributed to $17 \%$ of all MM deaths and is a common cause of death throughout the entire MM disease trajectory in patients of all ages. Death due to infection is highest prior to initiation of first-line therapy (46\%), though it also contributes to nearly one out of every five patient deaths by the fifth-line treatment [27].

\section{Timing of infection}

There is a bimodal distribution in the incidence of infections: the first peak during induction therapy and the second seen in the later course of advanced disease. Bacterial infection rates peak at 4-6 months following diagnosis (89.5 infections per 100 patientyears, /100PY) and again at 70-72 months (50 infections/100PY). Similarly, viral infection rates peak at 7-9 months following diagnosis (36 infections/100PY) and later at 52-54 months (37.5 infections/100PY). It is suspected that the rise in infection during this late stage of disease is a reflection of cumulative immunosuppression following multiple lines of therapy and use of intensive combination agents as salvage therapy [28].

Autologous stem-cell transplantation (ASCT), a standard frontline treatment for all eligible patients, represents another vulnerable period for infection. Transplant is typically preceded by high-dose chemotherapy, which places patients at a higher risk of infection due to chemotherapy-induced neutropenia [29].
Nearly all patients experience at least one febrile episode, often from an unknown source, during the post-transplant period [28].

\section{The changing spectrum of infection}

Beyond an increased incidence of infection, the types of infections observed in MM are now also changing over time with the introduction of novel anti-myeloma therapies.

Bacterial pathogens cause the majority of infections in MM. Compared to matched controls, MM patients have a seven-fold higher risk of developing a bacterial infection overall and an 11fold higher risk during the first year following diagnosis [24]. Historically, severe pneumonia and bloodstream infections from encapsulated pathogens, such as Streptococcus pneumoniae, were most commonly implicated $[30,31]$. However, vaccinations and, in some cases, antibiotic prophylaxis greatly reduced their incidence. Gram-positive pathogens are responsible for the majority (54.5\%) of infections during induction. However, more recent studies have shown that gram-negative pathogens are responsible for most infections (57.7\%) during disease progression, most commonly Escherichia coli (30.1\%). During those later disease stages, ASCT and salvage therapies that use high doses of conventional chemotherapy may disrupt mucosal integrity and cause profound neutropenia, thus increasing the risk of infection with gramnegative bacteria [32].

Patients with MM are also highly susceptible to viral infections. Compared to matched controls, MM patients have a 10-fold higher risk of viral infections overall and an 18-fold higher risk in the first year following diagnosis [24, 33]. Respiratory viruses are commonly seen, with rhinovirus observed most frequently in symptomatic MM patients. Influenza is associated with the highest morbidity and mortality and occurs at all stages of the disease. Reactivation of latent viruses, varicella zoster virus and hepatitis $B$ virus, is a newer concern for $\mathrm{MM}$ patients, particularly with proteasome inhibitor $(\mathrm{PI})$ use [34].

More recently, infection with the SARS-CoV-2 virus during the COVID-19 pandemic is a significant concern to cancer patients, who have poor outcomes. In a large international study, nearly one-third of cancer patients admitted with SARS-CoV-2 died [35]. Older patients and patients with hematologic malignancies (particularly those treated with recent chemotherapy) had increased risk of death [36]. A study of 100 infected MM patients hospitalized in New-York found a mortality rate of $24 \%$, which is in the higher range of reports from the general hospitalized population [37]. Patients with elevated inflammatory markers and severe hypogammaglobulinemia had a significantly higher mortality rate [38].

Previously, invasive fungal infections (IFIs) such as invasive aspergillosis were more commonly seen with conventional chemotherapy and were associated with a high mortality rate of nearly $50 \%$ [39]. With the introduction of novel anti-myeloma therapy, rates of $\mathrm{IFI}$ are relatively low (2.4\%), although the mortality rate remains high for infected patients. IFIs are largely seen with greater cumulative treatment exposure and disease burden and should be considered in the differential for these patients [40]. Other opportunistic infections, such as Pneumocystis jirovecii pneumonia (PCP), are also seen in $\mathrm{MM}$, ranging from 25-45 cases $/ 100,000$ patient-years [41]. Recently, we have reported evidence of other opportunistic cases, such as cryptosporidiosis [42].

\section{RISK FACTORS FOR INFECTION}

\section{Disease-related risk factors}

Deregulation and dysfunction of the immune system in MM makes patients not only more vulnerable to infections but also limits their response to fight infections (Fig. 2).

The innate immune system is the first line of defense against infection. Monocytes perform several key roles, such as 
Adaptive Immunity
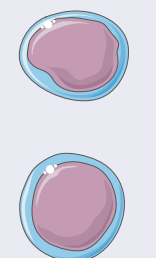

T-cell

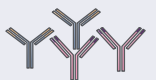

Antibodies

$$
\text { Oligoclonality }
$$

Decreased CD4/CD8 ratio

Defective Th1 function

Oligoclonal expansions of CD4+ and CD8+ leading to defective TCR

Reduce antibody production

Dendritic cells

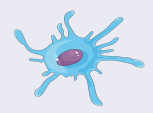
Dendritic cells

Low dendritic cell count Inhibition by MM microenvironment factors such as TGF- $\alpha$ IL-10, IL-6, VEGF, Muc-1, and Cox-2.

Innate Immunity

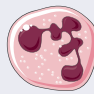

Neutrophils

Low neutrophil count

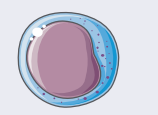

NK-cell

Low NK-cell count

Decline in NK cell cytotoxicity, secondary to high levels of M-proteins

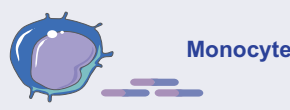
and soluble cytokine receptors activity

Low monocyte count Monocyte dysfunction: - high paraprotein - C3 dysfunction
Host factors

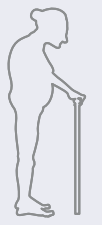

Treatment related factors

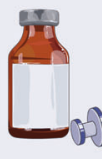

Immunosenescence

Nutrition status

ECOG

Co-morbidities

Fig. 2 Risk factors of infection in plasma cell disorders. Plasma cell disorders interfere with multiple immune actors from the adaptive and innate immune systems as well as dendritic cells. More indirectly, additional host factors such as immunosenescence, denutrition, or other comorbidities and treatment may further perturb efficiency of infection response.

chemotaxis, phagocytosis, cytokine production, and activation of T-cells and B-cells, which are constitutively impaired in MM and are further inhibited by elevated paraprotein levels [43]. Impaired activation of the complement system leads to diminished opsonization, phagocytosis, and pathogen clearance, which results in increased susceptibility to bacterial infections with encapsulated organisms [44, 45].

Natural killer (NK)-cells, which help stimulate an adaptive immune response through cytokine release, have preserved function in MGUS and NDMM with low disease burden. However, with increased disease burden, there is an associated decline in NK-cell cytotoxicity, thought to be due to high levels of monoclonal proteins and soluble cytokine receptors activity [46].

Dendritic cells act as messengers between the innate and adaptive immune systems. The number of circulating dendritic cells is suppressed in MM. The MM microenvironment additionally inhibits normal dendritic cell function [47].

The adaptive immune system employs both cell- and antibodymediated immunity to fight off pathogens, creating immunological memory to provide long-lasting protection. These functions are impaired in $\mathrm{MM}$, leading to higher risk of infection.

The number of circulating CD19+ B-cells is significantly decreased in MM and has been shown to inversely correlate with disease stage and to improve during remission or plateau phases [48]. MM patients also have immunoparesis, or suppression of polyclonal non-paraprotein immunoglobulins, which is associated with an increased risk of bacterial infection [49].

Significant abnormalities in T-cell count and function have also been described in MM. The CD4:CD8 ratio is reduced, either due to increased CD8+ cells in the bone marrow and circulation or 
decreased number of CD4+ cells [50]. There is also an imbalance of helper T-cells, which promote cell-mediated immunity (Th1) and antibody-mediated immunity (Th2) [51]. A loss of T-cell receptor diversity, with marked oligoclonal expansions of CD4+ and CD8+ T-cells, results in an impaired ability to recognize and mount an effective response to a wide range of pathogens $[52,53]$.

The interaction between myeloma tumor cells and the microenvironment is a new area of interest. Tumor cells and stromal cells interact via adhesion molecules and cytokine networks to promote tumor cell growth and drug resistance, in addition to angiogenesis and disordered bone metabolism. Additionally, there is increased production of numerous immunologically active factors, which play a role in the immune response to myeloma tumor cells and to pathogens [47].

\section{Host-related risk factors}

Patient-inherent factors, such as age and comorbidity burden, additionally increase the risk of infection in MM. Treatmentemergent (TE) infections are commonly seen; it is therefore critical to calculate an individual patient's risk in selecting an appropriate treatment. The prospective FIRST trial identified performance status, serum $\beta 2$-microglobulin, $\mathrm{LDH}$, and hemoglobin as prognostic of development of a first TE grade $\geq 3$ infection in the first four months of treatment ( $24 \%$ in high-risk vs. $7 \%$ in low-risk; $p<$ 0.0001 ) [54]. A retrospective UK study of 200 NDMM patients also found COPD and smoking are associated with a significantly higher incidence of infections [55].

Immunosenescence and age-related factors. Elderly patients, regardless of $\mathrm{MM}$, are particularly vulnerable to developing infections. They have higher morbidity and at least three-fold higher mortality rates compared to younger patients. This is likely multifactorial due to age-related immune dysfunction, decreased physiologic reserve, frailty, geriatric syndromes, cognitive dysfunction, and social isolation [56-58].

Aging is associated with dysfunction of both the innate and adaptive immune systems, also known as immunosenescence [49]. The cellular components of the innate immune system have decreased function with aging [43]. Neutrophils and macrophages have reduced chemotaxis, phagocytosis, and intracellular pathogen killing. NK-cells have decreased cytotoxic activity, although the increased number of NK-cells may compensate for this. Macrophages and dendritic cells also have diminished antigenpresenting function.

By comparison, age-related changes in the adaptive immune system are primarily due to changes in T-cell function related to involution of the thymus gland and phenotypic changes in bone marrow stem cells that limit T-cell clonal expansion [59]. With aging, stem cell precursors shift production from lymphoid to myeloid lineage. The relative frequency of memory B-cells and plasma cells decrease in the peripheral blood, while immature and naïve B-cells are unaffected [60]. The number of naïve T-cells is decreased, and there is a relative shift towards memory T-cells, which results in decreased T-cell diversity, thereby reducing the ability to respond to new distinct antigens $[61,62]$. This is likely to contribute to impaired antibody responses to pathogens and to vaccination in the elderly.

Comorbidity burden. Older MM patients frequently have preexisting comorbidities, such as diabetes mellitus or chronic kidney disease, which increase their baseline risk of infection. The development of MM may lead to additional organ dysfunction and comorbidity burden that will additionally increase their risk of infection. With initiation of MM treatment, the risk of infection may be further elevated due to treatment-induced neutropenia, transfusion-associated, glucocorticoid-induced hyperglycemia and immunosuppression, gastrointestinal mucosal damage from chemotherapy, renal failure from cast nephropathy and hypercalcemia, and respiratory compromise from vertebral collapse and use of opiate drugs [63].

\section{Treatment-related risk factors}

The type of MM-directed treatment also plays a role in the risk of infection, Table 1. The current induction treatment algorithm uses a combination of IMiDs and PIs with glucocorticoids. Transplanteligible patients are subsequently treated with high-dose chemotherapy and ASCT, followed by consolidation and maintenance therapy, typically again with IMiDs and PIs. Inevitably, most patients develop disease relapse, requiring additional therapies, each of which contributes to cumulative immunosuppression and higher risk of infectious complications. Infections significantly burden both transplant-eligible and transplant-ineligible patients. Curiously, the infection rates do not appear significantly higher in the upfront and relapse settings, Fig. 3, at least in the highly selected context of clinical trials.

IMiDs. The immunomodulatory drug thalidomide helped usher in a new era in MM treatment once it was discovered to induce marked responses. Structural analogs to thalidomide, lenalidomide and pomalidomide, were subsequently also approved to treat MM. IMiDs downregulate the transcription factor PU.1, which disrupts granulocyte differentiation and induces neutropenia [63]. Multiple large meta-analyses have demonstrated that MM patients treated with IMiD-based regimens have an increased risk of serious infection at all stages of treatment--induction (13.4\% in transplant-ineligible patients, $22.4 \%$ in transplant-eligible patients), maintenance (10.5\%), and relapsed/refractory (R/R) disease (16.6\%) [64]. A meta-analysis noted a more than two-fold risk of high-grade infection associated with lenalidomide use (RR 2.23, 95\% Cl: 1.71-2.91, $p<0.0001)$. [65]

Table 1. Rate of Infections from Phase 3 Randomized Clinical Trials of MM-Directed Therapy.

\begin{tabular}{|c|c|c|c|c|c|c|}
\hline & \multirow[t]{2}{*}{ Trial } & \multirow[t]{2}{*}{ Author, Year } & \multirow[t]{2}{*}{ Patients $(N)$} & \multirow[t]{2}{*}{ Regimen } & \multicolumn{2}{|c|}{ Rate of infections (\%) } \\
\hline & & & & & All grades & Grade $\geq 3$ \\
\hline \multirow[t]{2}{*}{$\begin{array}{l}\text { Age } \geq \\
65 \text { years }\end{array}$} & FIRST & $\begin{array}{l}\text { Benboubker, } 2014 \\
\text { [111] }\end{array}$ & 1623 & $\begin{array}{l}\text { Continuous Rd vs. Rd x } 18 \\
\text { cycles vs. MPT }\end{array}$ & & $\begin{array}{l}28.9 \text { vs. } 21.8 \\
\text { vs. } 17.2\end{array}$ \\
\hline & MAIA & Facon, 2019 [112] & 737 & DRd vs. Rd & 86.3 vs. 73.4 & 32.1 vs. 23.3 \\
\hline \multirow{4}{*}{$\begin{array}{l}\text { Age }< \\
65 \text { years }\end{array}$} & IFM2007-02 & Moreau, 2011 [113] & 199 & Vd vs. reduced VTd & 59 vs. 58 & 14 vs. 10 \\
\hline & SWOG S0777 & Durie, 2017 [114] & 525 & Rd vs. VRd & 26.5 vs. 28.2 & 13.7 vs. 14.5 \\
\hline & CASSIOPEIA & Moreau, 2019 [116] & 1085 & D-VTd vs. VTd & 65 vs. 57 & 22 vs. 20 \\
\hline & ENDURANCE E1A11 & Kumar, 2020 [117] & 1087 & KRd vs. VRd & & 13.9 vs. 9.3 \\
\hline
\end{tabular}

$R$ Lenalidomide, $d$ Dexamethasone, $M$ Melphalan, $P$ Prednisone, $T$ Thalidomide, $D$ Daratumumab, $V$ Bortezomib, $K$ Carfilzomib, $C$ Cyclophosphamide. 
A.

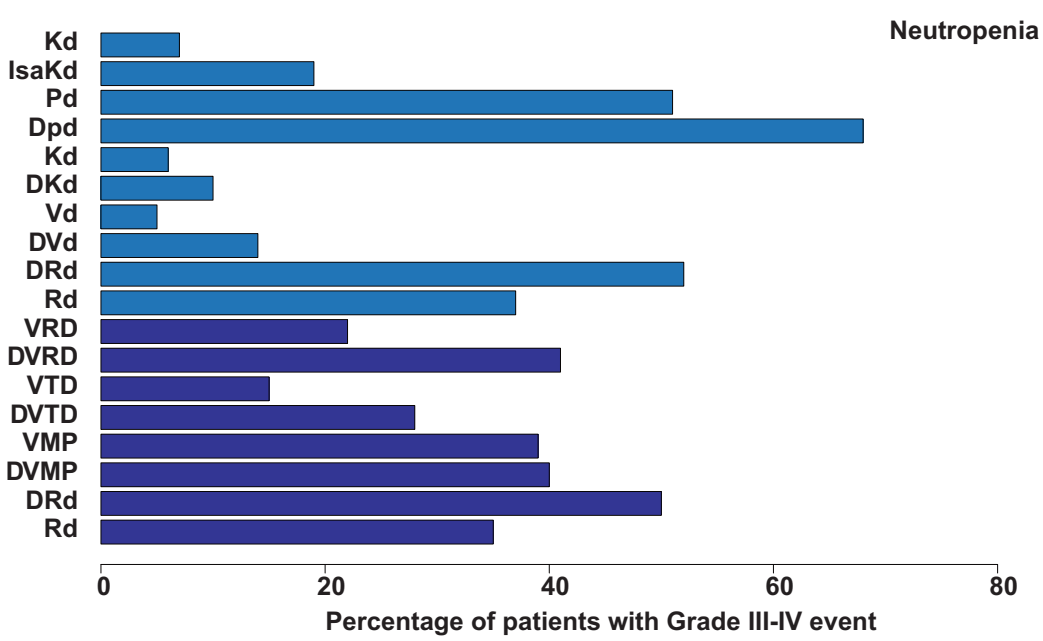

B.

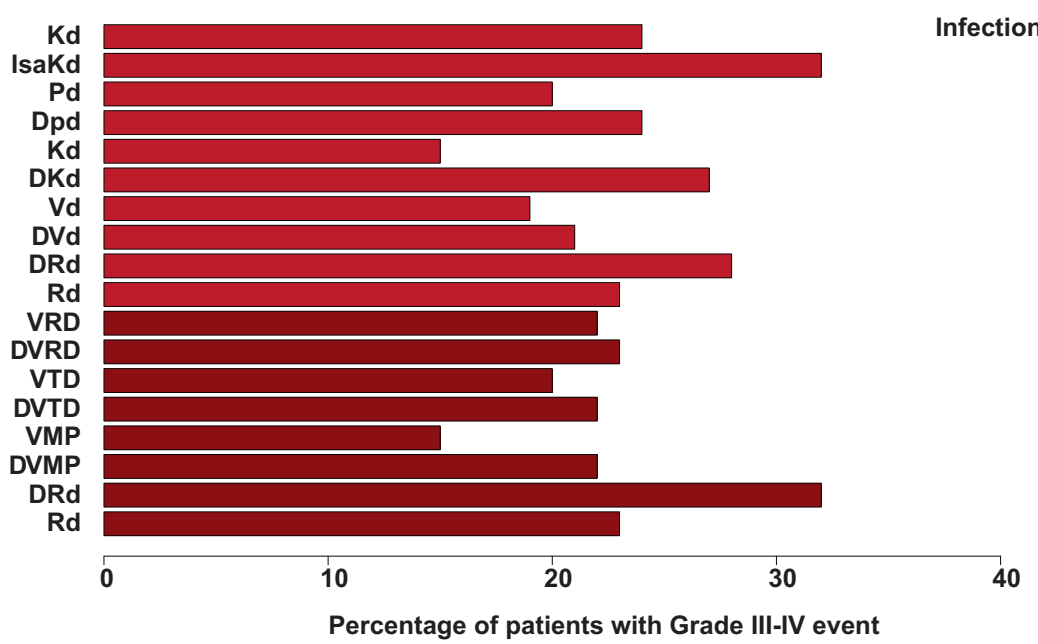

C.

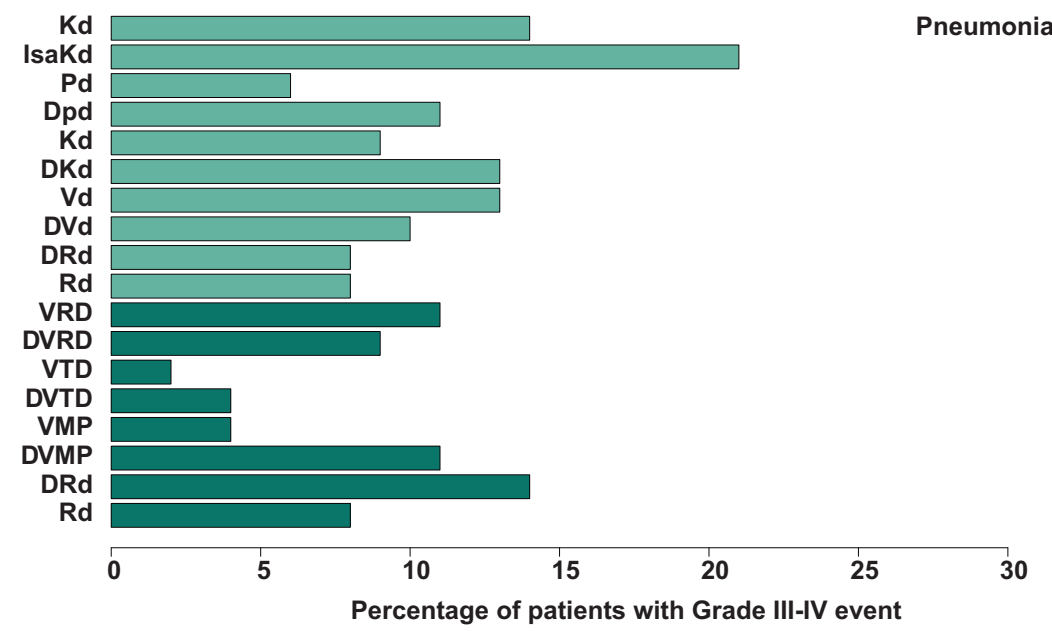

Fig. 3 Impact of disease stage and treatment regimen on infection in clinical trials. Proportion of patients with grade III-IV neutropenia (A), infection (B), or pneumonia (C) in newly diagnosed (dark) or relapsed/refractory (light) therapeutic trials.

However, this risk is less than that seen with conventional chemotherapy (RR 0.82, 95\% Cl: 0.72-0.9, $p<0.01$ ) [66].

The risk of infection varies depending on the specific type of IMiD. Maintenance lenalidomide use has twice the risk of serious infection compared to thalidomide use (RR 1.95, 95\% Cl: 1.07-3.37, $p=0.03$ )
[64]. Pomalidomide-based regimens have the highest risk of infection, observed in $23 \%$ of patients with $\mathrm{R} / \mathrm{R}$ disease. Lenalidomide and pomalidomide have a higher risk of therapy-induced neutropenia, which may contribute to this increased infection risk. In clinical practice, this should be weighed against other potential 
adverse effects, including risk of peripheral neuropathy and thrombosis, in determining the optimal IMiD for use.

Transplant eligibility was additionally found to be a risk factor for higher infection rates with IMiDs. This is surprising as transplantineligible patients are typically thought to have more risk factors for infection, such as older age, higher comorbidity burden, or poor functional status. Multiple meta-analyses have demonstrated that transplant-eligible patients have a higher risk of serious infection with IMiD-based induction therapy, compared to transplantineligible patients (13.4 vs. $22.4 \%$ [64], 11 vs. $14.8 \%$ [66]). The lower cumulative glucocorticoid dose used in transplant-ineligible patients in these studies is hypothesized to account for the lower observed infection rates, as high cumulative glucocorticoid doses are independently associated with increased infection risk in MM [28].

Proteasome Inhibitors. PIs disrupt the function of intracellular proteasomes and activation of NF-kB, resulting in selective depletion of T-cells and a decline in viral antigen presentation and thus leading to an increased risk of reactivation of viral infections [34, 67]. Bortezomib is a first in-class PI that is frequently used in combination with IMiDs and glucocorticoids as frontline therapy for MM. Although a large meta-analysis did not find an increased risk of severe infection in bortezomib-based induction therapy compared to conventional chemotherapy (RR 1.12, 95\% $\mathrm{Cl}$ : $0.89-1.40, p=0.34)$, there was a two-fold risk in severe infection when compared to thalidomide-based therapy (RR 2.03, $95 \%$ Cl: $1.45-2.89, p<0.01)$ [64].

Glucocorticoids. Glucocorticoids have represented a key component of MM therapy for many years. First used as monotherapy and later paired with conventional chemotherapy, they more recently have combined with novel agents, such as IMiDs and PIs. Glucocorticoid therapy increases the risk of all types of infections (bacterial, viral, and fungal) through a variety of mechanisms. The risk of infection is directly proportional to the dose of glucocorticoid use, with the highest risk seen in prednisone doses over $20 \mathrm{mg}$ daily [49]. Higher cumulative glucocorticoid doses further increase the risk of infection in $\mathrm{MM}$, as seen in a large population-based cohort study of 275,000 adults prescribed glucocorticoids for at least 15 days. These patients had statistically significant higher rates of cutaneous cellulitis (HR 2.21), herpes zoster infections (HR 2.37), bloodstream infections (HR 3.96), candidiasis (HR 4.93), and lower respiratory tract infections (HR 5.42), with $p<0.001$ for all comparisons. The risk of infection increased with age and was higher among those patients with diabetes and higher glucocorticoid doses [68].

Monoclonal Antibodies. Daratumumab, a monoclonal antibody directed against CD38, has been approved for MM treatment in the upfront and R/R settings. Daratumumab selectively depletes NK-cells, which also express CD38, and disrupts the innate immune response. A retrospective study noted that $39 \% \mathrm{R} / \mathrm{R}$ MM patients had infectious complications with daratumumab therapy, and $22 \%$ of the patients developed reactivation of latent viral infections, including herpes simplex virus (HSV), VZV, and cytomegalovirus (CMV) [69]. Similar results were seen prospectively in a phase II clinical trial in a relatively high-risk, heavily pretreated triple-R/R population [70]. Triplet combination therapies (particularly those containing daratumumab) lead to higher rates of neutropenia and grade III-IV infections and pneumonias compared to doublet combination therapies (Fig. 3). As myeloma is a chronic condition frequently necessitating continuous immunosuppressive treatment, continuous vigilance for infections is increasingly important.

Stem Cell Transplantation. Allogeneic stem cell transplantation was the first proven curative treatment for MM, but its use has been limited by high mortality rates [71]. ASCT is used instead as a standard frontline treatment for all eligible patients. Given high rates of significant transplant-associated myelosuppression, patients are at very high risk of infection. The spectrum of infections depends on time elapsed from the ASCT. Within the first 30 days, infections are primarily due to treatment-induced neutropenia, with bacteremia most common [49]. Although $94 \%$ of patients have episodes of neutropenic fever, only $30-40 \%$ have microbiological confirmation of an infectious source [72]. Historically gram-negative pathogens were common culprits, though gram-positive pathogens seem now more commonly seen, likely due to increased use of fluoroquinolone prophylaxis. Rates of IFIs are low $(0-2.7 \%)$, similar to that seen in transplant-ineligible MM patients $[73,74]$. Late infections occurring more than 30 days after ASCT, when neutrophil recovery has typically already occurred, are associated with decreased lymphocyte counts and impaired cellmediated immunity [49]. Nearly $80 \%$ of MM patients experience a late infection within 100 days post-ASCT [75]. Patients may also be susceptible to VZV and CMV infections due to deficits in CD4 cells [76].

CAR-T Therapy. Investigations of chimeric antigen receptormodified T-cell (CAR-T) therapy in MM have been directed towards B-cell maturation antigen (BCMA), which is preferentially expressed on plasma cells [77-79]. CAR-T is currently only approved in the R/R setting, where many patients have poor immune function from their underlying malignancy and prior cytotoxic treatments, thus increasing the risk of infection. In addition, the lymphodepleting chemotherapy administered immediately prior to CAR-T infusion can cause profound cytopenias and may impair mucosal barriers, thus raising the risk of infection. Further complicating the diagnostic picture, CAR-T can lead to cytokine release syndrome (CRS), which not only mimics sepsis but is also treated with steroids and/or tocilizumab, which both increase infection risk [80]. In the KarMMa study, which led to the approval of idecabtagene-vicleucel, $84 \%$ developed CRS and $69 \%$ developed infections (22\% grade $3-4$ ) [80].

\section{PREVENTATIVE STRATEGIES AGAINST INFECTION}

Preventative strategies including the use of prophylactic antimicrobial agents and vaccinations, have been devised to reduce the infection risk in MM but currently remain suboptimal.

\section{Vaccination}

Encapsulated bacteria. Due to impaired innate immune function, patients with MM have an increased risk of infection with encapsulated organisms. Therefore, preventable measures, such as vaccination against Streptococcus pneumoniae and Haemophilus influenzae type B, should be strongly considered [81]. The two pneumococcal vaccines available for adults are the 23-valent polysaccharide vaccine (PPV) and the 13-valent conjugated vaccine, which elicits a T-cell-dependent immune response and is more effective in producing memory B-cells. In immunocompromised patients, pneumococcal vaccinations are given as a prime-boost (PB) schedule: 13-valent, followed by 23-valent eight weeks or more apart. Response to at least one subtype of antibody was obtained in $85 \%$ of patients, to at least two subtypes in $65 \%$, and to at least three subtypes in $55 \%$. The anti-pneumococcal geometric mean concentration decreased significantly for all subtypes over time independently of treatment approaches [82]. Recommendations for further booster doses of PCV-13 vaccine are lacking.

Respiratory viruses. MM patients have an increased risk of community respiratory viruses, with influenza carrying the highest morbidity and mortality. The annual seasonal influenza vaccine is a critical preventative strategy, though the immune response to a 
620

single influenza vaccine may be inadequate. Strategies such as T-cell priming prior to ASCT and double doses of influenza vaccine have been studied to improve vaccination responses [83, 84]. A second dose of the standard-dose trivalent influenza vaccine was shown to more than double the seroprotection rate (14.6-31.3\%) [84]. Likewise, a high-dose vaccine induces significantly higher antibody responses and is now recommended for use in patients 65 years and older. Two doses of the high-dose trivalent influenza vaccine similarly improved responses in $\mathrm{MM}$, with total seroprotection of $47 \%$ seen after one dose and $65 \%$ after two doses. Improved clinical benefit was suggested by a laboratoryconfirmed influenza infection rate of $6 \%$, compared to an expected rate of at least $20 \%$ [85]. Clinical risk factors associated with an overall lower likelihood of achieving total seroconversion with the high-dose influenza vaccine include: (1) PCD requiring treatment, (2) immunoparesis, (3) active treatment with conventional chemotherapy, (4) disease response status less than a partial response, and (5) diagnosis of respiratory infections other than influenza during the influenza season. Patients with at least three risk factors appear to have the greatest benefit from the second high-dose vaccine [85].

Humoral immune responses to the SARS-CoV-2 vaccination are also depressed in myeloma patients. SARS-CoV-2 lgG antibodies were detected in $56 \%$ of patients after their first vaccination $(70 \%$ when measuring total antibody with anti-SARS-CoV-2 IgG, IgM, and $\lg A$ ) and were treatment dependent [86], which is lower than in the vaccine trials, where serological response was almost universal [87]. Boosters are now being recommended and the extent by which they increase immune responses remains to be determined.

Herpes Zoster. Herpes zoster vaccination is indicated for all individuals at least 50 years or older. As the live attenuated version of the VZV vaccine is contraindicated in immunocompromised patients, the recombinant glycoprotein E vaccine is used in MM patients and is superior in reducing the incidence of herpes zoster and post-herpetic neuralgia [88]. Herpes zoster vaccination in the peri-ASCT period can be highly effective. A phase 3 randomized trial of 560 patients found that four doses of the inactivated vaccine in the peri-transplant period resulted in lower rate of herpes zoster disease (8 vs. $21 \%$ ), herpes zoster-related complications ( 2 vs. $8 \%$ ), and post-herpetic neuralgia (1 vs. $3 \%)$, as compared to placebo [89].

Antibacterial Prophylaxis. MM patients, particularly those on immunosuppressive regimens, have a high risk of bacterial infections, likely secondary to prolonged neutropenia. Both the Infectious Diseases Society of America and the American Society of Clinical Oncology currently recommend fluoroquinolone prophylaxis in patients expected to have chemotherapy-induced neutropenia for greater than seven days [90]. As its efficacy may be limited by increasing rates of fluoroquinolone resistance, resistance should be monitored to better adapt preventive strategies.

MM patients who undergo ASCT have prolonged periods of neutropenia and are currently recommended to receive levofloxacin prophylaxis. A single-center retrospective study of MM patients found that use of levofloxacin prophylaxis after ASCT decreased rates of bacteremia $(14.7$ vs. $41.2 \%, p<0.001)$ and febrile neutropenia (60.9 vs. $91.6 \%, p<0.001)$ [91].

For MM patients not undergoing ASCT, antibacterial prophylaxis should be considered if they are expected to have prolonged neutropenia. A Japanese study of $80 \mathrm{MM}$ patients treated with bortezomib-based regimens demonstrated that daily oral levofloxacin significantly decreased severe infections compared to historical controls ( 17.5 vs. $30.9 \%, p=0.037$ ) [92].

More recently, the use of levofloxacin prophylaxis has been examined in the phase 3 , prospective, multicenter, double-blind
TEAMM study, which randomly assigned 977 NDMM patients to receive levofloxacin ( $500 \mathrm{mg}$ daily for 12 weeks) or placebo. After a median follow-up of 12 months, prophylaxis significantly reduced episodes of neutropenic fever ( 19 vs. $27 \%, p=0.0018$ ). Although there was an initial OS benefit at 12 weeks (98 vs. $95 \%, p=$ 0.0081 ), this was not sustained over 12 months (90 vs. $91 \%, p=$ 0.94 ) and was not attributed to infection. Additionally, the higher proportion of deaths with progressive disease in the levofloxacin group than in the control group (73 vs. 38\%) highlights the concerning possibility of an antibiotic-associated microbiomemediated impaired response to myeloma treatment [93].

Fluoroquinolones should be prescribed with caution, given the recognized risk of adverse outcomes related to mitochondrial toxicity, including tendonitis, irreversible neuropathies, and increased risk of antimicrobial-resistant colonization or infection. Furthermore, the emergence of clinically significant infections with gram-negative pathogens in patients receiving fluoroquinolone prophylaxis complicates initial management of neutropenic fever and most importantly contribute to overall acquisition of resistance at the population level.

\section{Antiviral Prophylaxis}

MM patients have an increased risk of viral infection, including both reactivation of latent viral infection and acquisition of new acute viral infection [34]. The highest risk for viral infection occurs in the post-transplant period, during maintenance therapy, and during disease progression, although patients can develop infection at any point during the disease course [28].

Nearly $50-60 \%$ of patients with malignancy have demonstrated prior exposure to HSV type 1 and 2 [94]. Prior to the use of antiviral prophylaxis, up to $80 \%$ of patients with hematological malignancy experienced HSV reactivation, but acyclovir use reduced the risk of HSV infection by $80-90 \%$ compared to placebo, with the number needed to treat of two. Valacyclovir has also been shown to be equally effective in prevention of HSV reactivation when compared to acyclovir [95-97].

Similarly, VZV is commonly encountered in MM patients, with nearly $80 \%$ having prior exposure with positive lgG levels [98]. The highest risk of reactivation is seen at 6-12 months after ASCT and is thought to be due to lymphocyte depletion with conditioning chemotherapy and subsequent delayed T lymphocyte recovery. Prior to antiviral prophylaxis, there was a four-fold increased risk of VZV reaction following ASCT [99]. Recent studies have shown that extended use of antiviral prophylaxis for up to one year post-ASCT significantly reduces the rate of VZV reactivation [100]. As a result, most transplant centers currently use antiviral prophylaxis (acyclovir or valacyclovir) for at least 6-12 months following ASCT to minimize this risk.

Bortezomib is also associated with a significantly higher rate of VZV reactivation (up to $36 \%$ ) [101]. As a result, it is generally now recommended to use prophylaxis with acyclovir or valacyclovir for the duration of $\mathrm{PI}$ therapy.

$\mathrm{HBV}$ reverse seroconversion, or the reappearance of HBV surface antigen in patients with resolved HBV infection, has been observed in up to $5.2 \%$ of $\mathrm{MM}$ patients with resolved HBV infection [102]. Over $50 \%$ of these patients had received ASCT and bortezomib therapy. Of note, patients without measurable HBV surface antibody (HBsAb) had a 4.6-fold higher risk of seroconversion. As a result, it is now recommended that MM patients with resolved HBV infection should receive prophylaxis for at least 6-12 months following ASCT. Extended use should be considered in patients with ongoing immunosuppressive therapy. For patients with resolved HBV infection undergoing bortezomib therapy, there is inadequate evidence to advise routine prophylaxis, but monitoring of HBsAb and HBV DNA levels every three months is recommended [34].

Although there is increased risk for infection with other viral pathogens with $M M$, the evidence for prophylaxis is currently 


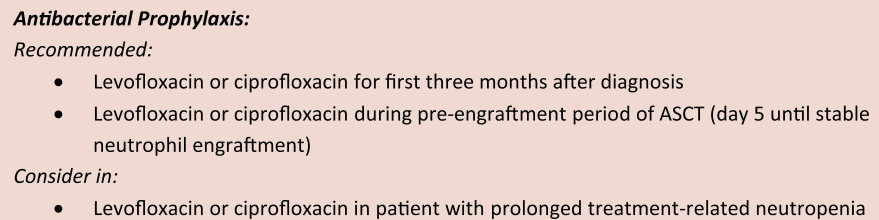

Fig. 4 Possible algorithm for antimicrobial prophylaxis and/vaccinations. Recommended antibacterial, antiviral, antifungal and vaccination for MM patients.

lacking and therefore only supportive measurements are recommended at this time.

\section{Other prophylaxis}

Patients with MM are at risk for IFls, particularly due to use of highdose glucocorticoids and other immunosuppressive therapy. Routine antifungal prophylaxis is generally not recommended, although it should be considered in select patients. Prophylaxis against PCP, most commonly with trimethoprim-sulfamethoxazole, is generally recommended if glucocorticoid dosing is equal to $20 \mathrm{mg}$ daily for at least one month [103]. Fluconazole is recommended during periods of neutropenia associated with ASCT [104]. Patients with greater cumulative treatment exposure and disease burden ( $\geq$ three lines of therapy in three years) have a particularly increased risk of IFIs ( $15 \%$ vs $2.4 \%$ overall in $\mathrm{MM}$ ) and may also benefit from antifungal prophylaxis [40].

Prophylactic treatment for Strongyloides stercoralis, a parasite endemic in many tropical, and subtropical, regions, should also be considered for select patients as immunosuppression could lead to hyperinfection syndrome and disseminated disease, which carry very high morbidity and mortality. All patients with strong epidemiological risk factors should be screened with serologic testing, and receive prophylaxis with oral ivermectin $(200 \mathrm{mcg} / \mathrm{kg}$ daily for two days, repeated at two weeks) [105].

\section{Immunoglobulin substitution therapy}

As MM patients commonly have reduced levels of polyclonal immunoglobulins, use of intravenous immunoglobulin (IVIG) has been proposed to reduce risk of recurrent infections. A few small placebo-controlled, randomized clinical trials showed significantly fewer serious infections in the IVIG arm [106, 107]. Notably, patients in these studies were treated with conventional chemotherapy without any antimicrobial prophylaxis, which are not standard in today's practice. More recently, a meta-analysis of nine randomized control trials comparing IVIG to control in MM with hypogammaglobulinemia found that while IVIG use is associated with a decreased risk of infection, there is no survival benefit. Two retrospective studies of prophylactic IVIG use in the peri-transplant period also did not show a benefit [108, 109].

In light of these findings, large randomized clinical trials are needed to justify widespread use of IVIG in the MM population. For now, it should only be considered in patients with severe hypogammaglobulinemia ( $\mathrm{lgG}<400 \mathrm{mg} / \mathrm{dL}$ ) and recurrent infections [110]. Similarly, small datasets report a role for sub-cutaneous IG.

\section{Future studies}

Patients with PCD have an increased risk of infection compared to the general population. In this era of multi-drug resistance and few antimicrobial options, we believe that clinicians must take a calibrated rather than an expansionist approach to antibiotic prophylaxis. We have suggested an algorithm (Fig. 4) to determine which PCD patients should receive antimicrobial prophylaxis and vaccinations.

The introduction of novel therapeutic agents has changed both the frequency and spectrum of infections seen in MM. Moving forward, a standardized approach and dedicated questions in 
clinical trials are needed to establish the best strategy for both treatment and prevention of infections. National population-based registries have allowed us to follow large cohorts of MM patients over time and may continue to provide more insight into new epidemiological patterns. For prospective clinical trials, it is important for infection to be considered as a secondary endpoint. Increased reporting of infectious complications both in R/R MM trials and phase IV post marketing are additionally needed.

\section{CONCLUSIONS}

Infection shape myeloma through complex interplay involving pathogens, chronic inflammation, and immune deregulation. Investigations of the role of the microbiome in $\mathrm{MM}$ are still relatively new and may yield additional findings, particularly for newer immune-based therapies. Patients with PCD have an increased risk of infection compared to the general population due to multiple factors related to the underlying disease, host age and comorbidities, and MM treatment. As new treatments for MM are developed, patients are living longer and it is critical to better understand, standardize, and evaluate the role of infection to gain maximum benefit from treatment.

\section{REFERENCES}

1. Parkin DM. The global health burden of infection-associated cancers in the year 2002. Int J Cancer. 2006;118:3030-44.

2. Grulich AE, Li Y, McDonald A, Correll PKL, Law MG, Kaldor JM. Rates of non-AIDSdefining cancers in people with HIV infection before and after AIDS diagnosis. AIDS. 2002;16:1155-61.

3. Briault S, Courtois-Capella M, Duarte F, Aucouturier P, Preud'Homme JL. Isotypy of serum monoclonal immunoglobulins in human immunodeficiency virusinfected adults. Clin Exp Immunol. 1988;74:182-4.

4. Collett D, Mumford L, Banner NR, Neuberger J, Watson C. Comparison of the incidence of malignancy in recipients of different types of organ: a UK Registry audit. Am J Transpl J Am Soc Transpl Am Soc Transpl Surg. 2010;10:1889-96.

5. Cowan AJ, Johnson CK, Libby EN. Plasma cell diseases and organ transplant: a comprehensive review. Am J Transpl. 2018;18:1046-58.

6. Mameli G, Fozza C, Niegowska M, Corda G, Ruda MF, Barraqueddu F, et al. Epstein-Barr virus infection is associated to patients with multiple myeloma and monoclonal gammopathy of undetermined significance. Leuk Lymphoma. 2017:58:466-9.

7. Rajput S, Minhas K, Azam I, Shaikh U, Hussain A, Lalani E-N. LMP1 expression in bone marrow trephines of patients with multiple myeloma confers a survival advantage. Leuk Lymphoma. 2019;60:1991-2001.

8. Lu F, Martin KA, Soldan SS, Kossenkov AV, Wickramasinghe P, Vladimirova O, et al. Defective Epstein-Barr Virus Genomes and Atypical Viral Gene Expression in B-Cell Lines Derived from Multiple Myeloma Patients. J Virol. 2021;95:e0008821.

9. Guihot A, Dupin N, Marcelin A-G, Gorin I, Bedin A-S, Bossi P, et al. Low T Cell Responses to Human Herpesvirus 8 in Patients with AIDS-Related and Classic Kaposi Sarcoma. J Infect Dis. 2006;194:1078-88.

10. Myeloma - Cancer Stat Facts. SEER. https://seer.cancer.gov/statfacts/html/ mulmy.html (accessed 7 Aug2020).

11. Boyle EM, Williams L, Blaney P, Ashby C, Bauer M, Walker BA et al. Improving prognostic assignment in older adults with multiple myeloma using acquired genetic features, clonal hemopoiesis and telomere length. Leukemia 2021: 1-4.

12. Nair S, Branagan AR, Liu J, Boddupalli CS, Mistry PK, Dhodapkar MV. Clonal Immunoglobulin against Lysolipids in the Origin of Myeloma. N. Engl J Med. 2016;374:555-61.

13. Moss JL, Pinto CN, Srinivasan S, Cronin KA, Croyle RT. Persistent Poverty and Cancer Mortality Rates: An Analysis of County-Level Poverty Designations. Cancer Epidemiol Biomark Prev Publ Am Assoc Cancer Res Cosponsored Am Soc Prev Oncol. 2020;29:1949-54.

14. Bosseboeuf A, Feron D, Tallet A, Rossi C, Charlier C, Garderet L et al. Monoclonal IgG in MGUS and multiple myeloma targets infectious pathogens. JCI Insight 2017; 2. https://doi.org/10.1172/jci.insight.95367.

15. Duberg A-S, Nordström M, Törner A, Reichard O, Strauss R, Janzon R, et al. NonHodgkin's lymphoma and other nonhepatic malignancies in Swedish patients with hepatitis C virus infection. Hepatol Baltim. Md. 2005;41:652-9.

16. Koduru S, Wong E, Strowig T, Sundaram R, Zhang L, Strout MP, et al. Dendritic cell-mediated activation-induced cytidine deaminase (AID)-dependent induction of genomic instability in human myeloma. Blood. 2012;119:2302-9.
17. Garrett WS. Cancer and the microbiota. Science. 2015;348:80-86.

18. Calcinotto A, Brevi A, Chesi M, Ferrarese R, Garcia Perez L, Grioni M, et al. Microbiota-driven interleukin-17-producing cells and eosinophils synergize to accelerate multiple myeloma progression. Nat Commun. 2018;9:4832.

19. Jasiński M, Biliński J, Basak GW. The Role of the Gut Microbiome in Pathogenesis, Biology, and Treatment of Plasma Cell Dyscrasias. Front Oncol. 2021;11:741376.

20. Antoine Pepeljugoski C, Morgan G, Braunstein M. Analysis of Intestinal Microbiome in Multiple Myeloma Reveals Progressive Dysbiosis Compared to MGUS and Healthy Individuals. Blood. 2019;134:3076.

21. Gopalakrishnan V, Helmink BA, Spencer CN, Reuben A, Wargo JA. The Influence of the Gut Microbiome on Cancer, Immunity, and Cancer Immunotherapy. Cancer Cell. 2018;33:570-80.

22. Pianko MJ, Devlin SM, Littmann ER, Chansakul A, Mastey D, Salcedo M, et al. Minimal residual disease negativity in multiple myeloma is associated with intestinal microbiota composition. Blood Adv. 2019;3:2040-4.

23. Kristinsson SY, Tang M, Pfeiffer RM, Björkholm M, Goldin LR, Blimark C, et al. Monoclonal gammopathy of undetermined significance and risk of infections: a population-based study. Haematologica. 2012;97:854-8.

24. Blimark C, Holmberg E, Mellqvist U-H, Landgren O, Björkholm M, Hultcrantz $M$, et al. Multiple myeloma and infections: a population-based study on 9253 multiple myeloma patients. Haematologica. 2015;100:107-13.

25. Augustson BM, Begum G, Dunn JA, Barth NJ, Davies F, Morgan G, et al. Early mortality after diagnosis of multiple myeloma: analysis of patients entered onto the United kingdom Medical Research Council trials between 1980 and 2002Medical Research Council Adult Leukaemia Working Party. J Clin Oncol Off J Am Soc. Clin Oncol. 2005;23:9219-26.

26. Xia J, Wang L, Zhou X, Wang J, Wang H, Guo H. Early mortality in elderly patients undergoing treatment for multiple myeloma in real-world practice. J Int Med Res. 2018;46:2230-7.

27. Mohty M, Cavo M, Fink L, Gonzalez-McQuire S, Leleu $H$, Mateos M-V, et al. Understanding mortality in multiple myeloma: Findings of a European retrospective chart review. Eur J Haematol. 2019;103:107-15.

28. Teh BW, Harrison SJ, Worth LJ, Spelman T, Thursky KA, Slavin MA. Risks, severity and timing of infections in patients with multiple myeloma: a longitudinal cohort study in the era of immunomodulatory drug therapy. $\mathrm{Br} \mathrm{J}$ Haematol. 2015;171:100-8.

29. Lenhoff S, Hjorth M, Holmberg E, Turesson I, Westin J, Nielsen JL, et al. Impact on survival of high-dose therapy with autologous stem cell support in patients younger than 60 years with newly diagnosed multiple myeloma: a populationbased study. Nordic Myeloma Study Group. Blood. 2000;95:7-11.

30. Hargreaves RM, Lea JR, Griffiths H, Faux JA, Holt JM, Reid C, et al. Immunological factors and risk of infection in plateau phase myeloma. J Clin Pathol. 1995;48:260-6.

31. Offidani M, Corvatta L, Polloni C, Gentili S, Brioni A, Visani G, et al. Infectious complications in patients with multiple myeloma treated with new drug combinations containing thalidomide. Leuk Lymphoma. 2011;52:776-85.

32. Teh BW, Harrison SJ, Slavin MA, Worth LJ. Epidemiology of bloodstream infections in patients with myeloma receiving current era therapy. Eur J Haematol. 2017;98:149-53.

33. Chanan-Khan A, Sonneveld P, Schuster MW, Stadtmauer EA, Facon T, Harousseau J-L, et al. Analysis of herpes zoster events among bortezomib-treated patients in the phase III APEX study. J Clin Oncol Off J Am Soc. Clin Oncol. 2008;26:4784-90.

34. Teh BW, Slavin MA, Harrison SJ, Worth LJ. Prevention of viral infections in patients with multiple myeloma: the role of antiviral prophylaxis and immunization. Expert Rev Anti Infect Ther. 2015;13:1325-36.

35. Chari A, Samur MK, Martinez-Lopez J, Cook G, Biran N, Yong K, et al. Clinical features associated with COVID-19 outcome in multiple myeloma: first results from the International Myeloma Society data set. Blood. 2020;136:3033-40.

36. Lee LYW, Cazier J-B, Starkey T, Briggs SEW, Arnold R, Bisht V et al. COVID-19 prevalence and mortality in patients with cancer and the effect of primary tumour subtype and patient demographics: a prospective cohort study. Lancet Oncol 2020. https://doi.org/10.1016/S1470-2045(20)30442-3.

37. Hultcrantz M, Richter J, Rosenbaum C, Patel D, Smith E, Korde N et al. COVID-19 infections and outcomes in patients with multiple myeloma in New York City: a cohort study from five academic centers. MedRxiv Prepr Serv Health Sci 2020. https://doi.org/10.1101/2020.06.09.20126516.

38. Wang B, Van Oekelen O, Mouhieddine TH, Del Valle DM, Richter J, Cho HJ et al. A tertiary center experience of multiple myeloma patients with COVID-19: lessons learned and the path forward. MedRxiv Prepr Serv Health Sci 2020. https://doi. org/10.1101/2020.06.04.20122846.

39. Lortholary O, Ascioglu S, Moreau P, Herbrecht R, Marinus A, Casassus P, et al. Invasive aspergillosis as an opportunistic infection in nonallografted patients with multiple myeloma: a European Organization for Research and Treatment of Cancer/ Invasive Fungal Infections Cooperative Group and the 
Intergroupe Français du Myélome. Clin Infect Dis Publ Infect Dis Soc Am. 2000;30:41-46

40. Teh BW, Teng JC, Urbancic K, Grigg A, Harrison SJ, Worth LJ, et al. Invasive fungal infections in patients with multiple myeloma: a multi-center study in the era of novel myeloma therapies. Haematologica. 2015;100:e28-31.

41. Fillatre $P$, Decaux $O$, Jouneau S, Revest M, Gacouin A, Robert-Gangneux F, et al. Incidence of Pneumocystis jiroveci pneumonia among groups at risk in HIVnegative patients. Am J Med. 2014;127:e11-17.

42. Demonchy J, Cordier C, Fréalle E, Demarquette H, Herbaux C, Escure G, et al. Case Report: Two Cases of Cryptosporidiosis in Heavily Pretreated Patients With Myeloma. Clin Lymphoma Myeloma Leuk. 2021;21:e545-e547.

43. Mainwaring CJ, Williams MA, Singer CR, Lush RJ, Smith JG, Haynes $C L$, et al. Monocyte dysfunction in patients with multiple myeloma and lymphoplasmacytic disorders is related to serum paraprotein levels. Br J Haematol. 1999;105:948-54.

44. Cheson BD, Walker HS, Heath ME, Gobel RJ, Janatova J. Defective binding of the third component of complement (C3) to Streptococcus pneumoniae in multiple myeloma. Blood. 1984;63:949-57.

45. Cheson BD, Plass RR, Rothstein G. Defective opsonization in multiple myeloma. Blood. 1980;55:602-6.

46. Godfrey J, Benson DM. The role of natural killer cells in immunity against multiple myeloma. Leuk Lymphoma. 2012;53:1666-76.

47. Pratt G, Goodyear O, Moss P. Immunodeficiency and immunotherapy in multiple myeloma. Br J Haematol. 2007;138:563-79.

48. Schütt $P$, Brandhorst $D$, Stellberg $W$, Poser $M$, Ebeling $P$, Müller $S$, et al. Immune parameters in multiple myeloma patients: influence of treatment and correlation with opportunistic infections. Leuk Lymphoma. 2006:47:1570-82.

49. Teh BW, Harrison SJ, Pellegrini M, Thursky KA, Worth LJ, Slavin MA. Changing treatment paradigms for patients with plasma cell myeloma: impact upon immune determinants of infection. Blood Rev. 2014;28:75-86.

50. Mills KH, Cawley JC. Abnormal monoclonal antibody-defined helper/suppressor T-cell subpopulations in multiple myeloma: relationship to treatment and clinical stage. Br J Haematol. 1983;53:271-5.

51. Tete SM, Bijl M, Sahota SS, Bos NA. Immune defects in the risk of infection and response to vaccination in monoclonal gammopathy of undetermined significance and multiple myeloma. Front Immunol. 2014;5:257.

52. Moss P, Gillespie G, Frodsham P, Bell J, Reyburn H. Clonal populations of CD4+ and CD8+ T cells in patients with multiple myeloma and paraproteinemia. Blood. 1996;87:3297-306.

53. Joshua D, Suen H, Brown R, Bryant C, Ho PJ, Hart D, et al. The T Cell in Myeloma. Clin Lymphoma Myeloma Leuk. 2016;16:537-42.

54. Dumontet C, Hulin C, Dimopoulos MA, Belch A, Dispenzieri A, Ludwig H, et al. A predictive model for risk of early grade $\geq 3$ infection in patients with multiple myeloma not eligible for transplant: analysis of the FIRST trial. Leukemia. 2018;32:1404-13.

55. Djebbari F, Panitsas F, Eyre TA, Prodger C, Davies F, Burton K et al. Infectionrelated morbidity in a large study of transplant non-eligible newly diagnosed myeloma patients treated with UK standard of care. Haematologica 2020. https://doi.org/10.3324/haematol.2019.240762.

56. Yoshikawa TT. Epidemiology and unique aspects of aging and infectious diseases. Clin Infect Dis Publ Infect Dis Soc Am. 2000;30:931-3.

57. Nucci $M$, Anaissie E. Infections in patients with multiple myeloma in the era of high-dose therapy and novel agents. Clin Infect Dis Publ Infect Dis Soc Am. 2009:49:1211-25.

58. Solana R, Tarazona R, Gayoso I, Lesur O, Dupuis G, Fulop T. Innate immunosenescence: effect of aging on cells and receptors of the innate immune system in humans. Semin Immunol. 2012;24:331-41.

59. Castle SC. Clinical relevance of age-related immune dysfunction. Clin Infect Dis Publ Infect Dis Soc Am. 2000;31:578-85.

60. Pritz T, Lair J, Ban M, Keller M, Weinberger B, Krismer M, et al. Plasma cell numbers decrease in bone marrow of old patients. Eur J Immunol. 2015;45:738-46.

61. Montecino-Rodriguez E, Berent-Maoz B, Dorshkind K. Causes, consequences, and reversal of immune system aging. J Clin Invest. 2013;123:958-65.

62. Pratt G, Goodyear O, Moss P. Immunodeficiency and immunotherapy in multiple myeloma. Br J Haematol. 2007;138:563-79.

63. Pal R, Monaghan SA, Hassett AC, Mapara MY, Schafer P, Roodman GD, et al. Immunomodulatory derivatives induce PU.1 down-regulation, myeloid maturation arrest, and neutropenia. Blood. 2010;115:605-14.

64. Teh BW, Harrison SJ, Worth LJ, Thursky KA, Slavin MA. Infection risk with immunomodulatory and proteasome inhibitor-based therapies across treatment phases for multiple myeloma: A systematic review and meta-analysis. Eur J Cancer Oxf Engl 1990. 2016;67:21-37.

65. Ying $L$, YinHui T, Yunliang $Z$, Sun $H$. Lenalidomide and the risk of serious infection in patients with multiple myeloma: a systematic review and metaanalysis. Oncotarget. 2017;8:46593-600.
66. Chen M, Zhao Y, Xu C, Wang X, Zhang X, Mao B. Immunomodulatory drugs and the risk of serious infection in multiple myeloma: systematic review and metaanalysis of randomized and observational studies. Ann Hematol. 2018;97:925-44.

67. Li L, Wang L. Multiple Myeloma: What Do We Do About Immunodeficiency? J Cancer. 2019;10:1675-84.

68. Fardet L, Petersen I, Nazareth I. Common Infections in Patients Prescribed Systemic Glucocorticoids in Primary Care: A Population-Based Cohort Study. PLoS Med. 2016;13:e1002024.

69. Nahi H, Chrobok M, Gran C, Lund J, Gruber A, Gahrton G, et al. Infectious complications and NK cell depletion following daratumumab treatment of Multiple Myeloma. PloS One. 2019;14:e0211927.

70. Boyle EM, Leleu X, Petillon M-O, Karlin L, Doyen C, Demarquette H, et al. Daratumumab and dexamethasone is safe and effective for triple refractory myeloma patients: final results of the IFM 2014-04 (Etoile du Nord) trial. Br J Haematol. 2019;187:319-27.

71. Bensinger WI, Buckner CD, Anasetti C, Clift R, Storb R, Barnett T, et al. Allogeneic marrow transplantation for multiple myeloma: an analysis of risk factors on outcome. Blood. 1996;88:2787-93.

72. Ketterer N, Espinouse D, Chomarat M, Dumontet C, Moullet I, Rieux C, et al. Infections following peripheral blood progenitor cell transplantation for lymphoproliferative malignancies: etiology and potential risk factors. Am J Med. 1999;106:191-7.

73. Reich G, Mapara MY, Reichardt P, Dörken B, Maschmeyer G. Infectious complications after high-dose chemotherapy and autologous stem cell transplantation: comparison between patients with lymphoma or multiple myeloma and patients with solid tumors. Bone Marrow Transpl. 2001;27:525-9.

74. Kolbe K, Domkin D, Derigs HG, Bhakdi S, Huber C, Aulitzky WE. Infectious complications during neutropenia subsequent to peripheral blood stem cell transplantation. Bone Marrow Transpl. 1997;19:143-7.

75. Gorschlüter M, Glasmacher A, Sarazin S, Hackbarth F, Hoebert E, Orlopp K, et al. CD4+ T lymphocyte counts after autologous transplantation in multiple myeloma: a retrospective study. Leuk Lymphoma. 2007;48:506-12.

76. Steingrimsdottir $H$, Gruber $A$, Kalin $M$, Björkholm $M$. Late infections after blood progenitor cell transplantation in patients with multiple myeloma. Am J Med. 2001;110:329-30.

77. Ghosh A, Mailankody S, Giralt SA, Landgren CO, Smith EL, Brentjens RJ. CAR T cell therapy for multiple myeloma: where are we now and where are we headed? Leuk Lymphoma. 2018;59:2056-67.

78. Hill JA, Li D, Hay KA, Green ML, Cherian S, Chen X, et al. Infectious complications of CD19-targeted chimeric antigen receptor-modified T-cell immunotherapy. Blood. 2018;131:121-30.

79. Brudno JN, Kochenderfer JN. Toxicities of chimeric antigen receptor T cells: recognition and management. Blood. 2016;127:3321-30.

80. Munshi NC, Anderson J, Larry D, Shah N, Jagannath S, Berdeja JG, Lonial S, et al. Idecabtagene vicleucel (ide-cel; bb2121), a BCMA-targeted CAR T-cell therapy, in patients with relapsed and refractory multiple myeloma (RRMM): Initial KarMMa results. J Clin Oncol. 2020;38:8503.

81. La Torre G, Mannocci A, Colamesta V, D'Egidio V, Sestili C, Spadea A. Influenza and Pneumococcal Vaccination in Hematological Malignancies: a Systematic Review of Efficacy, Effectiveness, and Safety. Mediterr J Hematol Infect Dis. 2016;8:e2016044.

82. Renaud L, Schraen S, Fouquet G, Guidez S, Demarquette $H$, Nudel M, et al. Response to pneumococcal vaccination in multiple myeloma. Cancer Med. 2019;8:3822-30.

83. Stadtmauer EA, Vogl DT, Luning Prak E, Boyer J, Aqui NA, Rapoport AP, et al. Transfer of influenza vaccine-primed costimulated autologous $T$ cells after stem cell transplantation for multiple myeloma leads to reconstitution of influenza immunity: results of a randomized clinical trial. Blood. 2011;117:63-71.

84. Hahn M, Schnitzler P, Schweiger B, Kunz C, Ho AD, Goldschmidt H, et al. Efficacy of single versus boost vaccination against influenza virus in patients with multiple myeloma. Haematologica. 2015;100:e285-88.

85. Branagan AR, Duffy E, Albrecht RA, Cooper DL, Seropian S, Parker TL, et al Clinical and serologic responses following a two dose series of high-dose influenza vaccine in plasma cell disorders: a prospective, single-arm trial. Clin Lymphoma Myeloma Leuk. 2017;17:296-304.

86. Terpos E, Gavriatopoulou M, Ntanasis-Stathopoulos I, Briasoulis A, Gumeni S, Malandrakis $P$, et al. The neutralizing antibody response post COVID-19 vaccination in patients with myeloma is highly dependent on the type of antimyeloma treatment. Blood. Cancer J. 2021;11:1-9.

87. Bird S, Panopoulou A, Shea RL, Tsui M, Saso R, Sud A, et al. Response to first vaccination against SARS-CoV-2 in patients with multiple myeloma. Lancet Haematol. 2021;8:e389-92.

88. McGirr A, Widenmaier R, Curran D, Espié E, Mrkvan T, Oostvogels $L$, et al. The comparative efficacy and safety of herpes zoster vaccines: A network metaanalysis. Vaccine. 2019;37:2896-909. 
89. Winston DJ, Mullane KM, Cornely OA, Boeckh MJ, Brown JW, Pergam SA, et al. Inactivated varicella zoster vaccine in autologous haemopoietic stem-cell transplant recipients: an international, multicentre, randomised, double-blind, placebo-controlled trial. Lancet Lond Engl. 2018;391:2116-27.

90. Taplitz RA, Kennedy EB, Bow EJ, Crews J, Gleason C, Hawley DK, et al. Antimicrobial Prophylaxis for Adult Patients With Cancer-Related Immunosuppression: ASCO and IDSA Clinical Practice Guideline Update. J Clin Oncol Off J Am Soc. Clin Oncol. 2018;36:3043-54.

91. Satlin MJ, Vardhana S, Soave R, Shore TB, Mark TM, Jacobs SE, et al. Impact of Prophylactic Levofloxacin on Rates of Bloodstream Infection and Fever in Neutropenic Patients with Multiple Myeloma Undergoing Autologous Hematopoietic Stem Cell Transplantation. Biol Blood Marrow Transpl J Am Soc Blood Marrow Transpl. 2015;21:1808-14.

92. Jung S-H, Kang S-J, Jang H-C, Ahn J-S, Yang D-H, Lee S-S, et al. Effect of levofloxacin prophylaxis for prevention of severe infections in multiple myeloma patients receiving bortezomib-containing regimens. Int J Hematol. 2014;100:473-7.

93. Drayson MT, Bowcock S, Planche T, lqbal G, Pratt G, Yong K, et al. Levofloxacin prophylaxis in patients with newly diagnosed myeloma (TEAMM): a multicentre, double-blind, placebo-controlled, randomised, phase 3 trial. Lancet Oncol. 2019;20:1760-72.

94. Yahav D, Gafter-Gvili A, Muchtar E, Skalsky K, Kariv G, Yeshurun M, et al. Antiviral prophylaxis in haematological patients: systematic review and meta-analysis. Eur J Cancer Oxf Engl 1990. 2009;45:3131-48.

95. Glenny A-M, Fernandez Mauleffinch LM, Pavitt S, Walsh T Interventions for the prevention and treatment of herpes simplex virus in patients being treated for cancer. Cochrane Database Syst Rev 2009;CD006706.

96. Dignani MC, Mykietiuk A, Michelet $M$, Intile $D$, Mammana $L$, Desmery $P$, et al. Valacyclovir prophylaxis for the prevention of Herpes simplex virus reactivation in recipients of progenitor cells transplantation. Bone Marrow Transpl. 2002;29:263-7.

97. Eisen D, Essell J, Broun ER, Sigmund D, DeVoe M. Clinical utility of oral valacyclovir compared with oral acyclovir for the prevention of herpes simplex virus mucositis following autologous bone marrow transplantation or stem cell rescue therapy. Bone Marrow Transpl. 2003;31:51-55.

98. Teh B, Worth L, Harrison S, Spelman T, Thursky K, Slavin M The timing and clinical predictors of herpesvirus infections in patients with myeloma in the setting of antiviral prophylaxis. 2015.

99. Erard V, Guthrie KA, Varley C, Heugel J, Wald A, Flowers MED, et al. One-year acyclovir prophylaxis for preventing varicella-zoster virus disease after hematopoietic cell transplantation: no evidence of rebound varicella-zoster virus disease after drug discontinuation. Blood. 2007;110:3071-7.

100. Truong Q, Veltri L, Kanate AS, Hu Y, Craig M, Hamadani M, et al. Impact of the duration of antiviral prophylaxis on rates of varicella-zoster virus reactivation disease in autologous hematopoietic cell transplantation recipients. Ann Hematol. 2014;93:677-82.

101. Pour L, Adam Z, Buresova L, Krejci M, Krivanova A, Sandecka V, et al. Varicellazoster virus prophylaxis with low-dose acyclovir in patients with multiple myeloma treated with bortezomib. Clin Lymphoma Myeloma. 2009;9:151-3.

102. Lee JY, Lim SH, Lee M-Y, Kim H, Sinn DH, Gwak G-Y, et al. Hepatitis B reactivation in multiple myeloma patients with resolved hepatitis $B$ undergoing chemotherapy. Liver Int Off J Int Assoc Study. Liver. 2015;35:2363-9.

103. Worth LJ, Dooley MJ, Seymour JF, Mileshkin L, Slavin MA, Thursky KA. An analysis of the utilisation of chemoprophylaxis against Pneumocystis jirovecii pneumonia in patients with malignancy receiving corticosteroid therapy at a cancer hospital. Br J Cancer. 2005;92:867-72.

104. Slavin MA, Thursky KA, Worth LJ, Chang CC, Morrissey CO, Blyth CC, et al. Introduction to the updated Australian and New Zealand consensus guidelines for the use of antifungal agents in the haematology/oncology setting, 2014. Intern Med J. 2014;44:1267-76.

105. La Hoz RM, Morris MI, Infectious AST. Diseases Community of Practice. Intestinal parasites including Cryptosporidium, Cyclospora, Giardia, and Microsporidia, Entamoeba histolytica, Strongyloides, Schistosomiasis, and Echinococcus: Guidelines from the American Society of Transplantation Infectious Diseases Community of Practice. Clin Transpl. 2019;33:e13618.

106. Chapel HM, Lee M, Hargreaves R, Pamphilon DH, Prentice AG. Randomised trial of intravenous immunoglobulin as prophylaxis against infection in plateauphase multiple myeloma. The UK Group for Immunoglobulin Replacement Therapy in Multiple Myeloma. Lancet Lond Engl. 1994;343:1059-63.

107. Musto $P$, Brugiatelli $M$, Carotenuto $M$. Prophylaxis against infections with intravenous immunoglobulins in multiple myeloma. Br J Haematol. 1995;89:945-6.

108. Blombery P, Prince HM, Worth LJ, Main J, Yang M, Wood EM, et al. Prophylactic intravenous immunoglobulin during autologous haemopoietic stem cell transplantation for multiple myeloma is not associated with reduced infectious complications. Ann Hematol. 2011;90:1167-72.

109. Park S, Jung CW, Jang JH, Kim SJ, Kim WS, Kim K. Incidence of infection according to intravenous immunoglobulin use in autologous hematopoietic stem cell transplant recipients with multiple myeloma. Transpl Infect Dis J Transpl Soc. 2015;17:679-87.

110. Girmenia C, Cavo M, Offidani M, Scaglione F, Corso A, Di Raimondo F, et al. Management of infectious complications in multiple myeloma patients: Expert panel consensus-based recommendations. Blood Rev. 2019;34:84-94.

111. Benboubker L, Dimopoulos MA, Dispenzieri A, Catalano J, Belch AR, Cavo M, et al. Lenalidomide and dexamethasone in transplant-ineligible patients with myeloma. N. Engl J Med. 2014;371:906-17.

112. Facon T, Kumar S, Plesner T, Orlowski RZ, Moreau $P$, Bahlis $N$, et al. Daratumumab plus Lenalidomide and Dexamethasone for Untreated Myeloma. N. Engl J Med. 2019;380:2104-15.

113. Moreau P, Avet-Loiseau H, Facon T, Attal M, Tiab M, Hulin C, et al. Bortezomib plus dexamethasone versus reduced-dose bortezomib, thalidomide plus dexamethasone as induction treatment before autologous stem cell transplantation in newly diagnosed multiple myeloma. Blood. 2011;118:5752-8.

114. Durie BGM, Hoering A, Abidi MH, Rajkumar SV, Epstein J, Kahanic SP, et al. Bortezomib with lenalidomide and dexamethasone versus lenalidomide and dexamethasone alone in patients with newly diagnosed myeloma without intent for immediate autologous stem-cell transplant (SWOG S0777): a randomised, open-label, phase 3 trial. Lancet Lond Engl. 2017;389:519-27.

115. Moreau P, Hulin C, Macro M, Caillot D, Chaleteix C, Roussel M, et al. VTD is superior to VCD prior to intensive therapy in multiple myeloma: results of the prospective IFM2013-04 trial. Blood. 2016;127:2569-74.

116. Moreau $P$, Attal $M$, Hulin $C$, Arnulf $B$, Belhadj $K$, Benboubker $L$, et al. Bortezomib, thalidomide, and dexamethasone with or without daratumumab before and after autologous stem-cell transplantation for newly diagnosed multiple myeloma (CASSIOPEIA): a randomised, open-label, phase 3 study. Lancet Lond Engl. 2019;394:29-38.

117. Kumar SK, Jacobus SJ, Cohen AD, Weiss M, Callander N, Singh AK et al. Carfilzomib or bortezomib in combination with lenalidomide and dexamethasone for patients with newly diagnosed multiple myeloma without intention for immediate autologous stem-cell transplantation (ENDURANCE): a multicentre, open-label, phase 3, randomised, controlled trial. Lancet Oncol 2020. https://doi. org/10.1016/S1470-2045(20)30452-6.

\section{AUTHOR CONTRIBUTIONS}

EMB: designed the project. JC and EMB: reviewed the literature, wrote the manuscript. MB, LW, BB, DK, AS, BR, SA, GJM, FED: provided feedback, approved the manuscript.

\section{COMPETING INTERESTS}

Jessica Caro: None. Marc Braunstein: Research Support - Janssen, Celgene; Advisory: ADC Therapeutics, Amgen, AstraZeneca, Celgene, Epizyme, Janssen, Karyopharm, Morphosys, Pfizer, Takeda, TG Therapeutics, Verastem; Faculty Bureau: Janssen. Louis Williams: None. Benedetto Bruno: None. David Kaminetzky: None. Ariel Siegel: None. Beatrice Razzo: None. Serge Alfandari: None. Gareth J Morgan: Janssen - research funding; Bristol-Myers Squibb - consultancy, honoraria; Takeda - consultancy, honoraria; Celgene Corporation - consultancy, honoraria, research funding; Roche consultancy, honoraria; Amgen - consultancy, honoraria; GSK - consultancy, honoraria; Karyopharm - consultancy, honoraria. Faith E Davies: Adaptive - honoraria; Celgene Corporation - consultancy, honoraria, research funding; Janssen consultancy, honoraria; Oncopeptide - consultancy, honoraria; Roche - consultancy, honoraria; Sanofi - consultancy, honoraria; Takeda - consultancy, honoraria. Eileen M Boyle: None.

\section{ADDITIONAL INFORMATION}

Correspondence and requests for materials should be addressed to Eileen M. Boyle.

Reprints and permission information is available at http://www.nature.com/ reprints

Publisher's note Springer Nature remains neutral with regard to jurisdictional claims in published maps and institutional affiliations. 